\title{
THE SEISMIC BEHAVIOUR OF PLYWOOD SHEATHED SHEARWALLS
}

\author{
J.A. Dean*, W. G. Stewart* and A. J. Carr*
}

ABSTRACT

\begin{abstract}
PIywood sheathed timber shearwalls are commonly incorporated in timber structures to resist wind and earthquake induced latepal forces. Such shearwalls are classified in the NZS 4203:1984 earthquake loading provisions as being ductile and are currently
designed to earthquake load levels of $25 \%$ of the smoothed elastic response spegtrum force, i.e. corresponding to $S M=1$ in terms of NZS 4203:1984 notation.

However, a case study is examined which illustrates that compliance with the NZS 3603:1981 permissible wind-seismic connection load and stress levels does not ensure ductility. Recommendations are made for a capacity design procedure in which the sheathing nailing acts as the ductile load limiting element. Even when this is achieved, cyclic loading of the walls at seismic design load levels causes progressive degrading of strength and stiffness properties resulting in a pinched hysteretic loop. The displacement demands on walls in which this occurs when subjected to a design intensity earthquake ground motion are compared in the paper with the corresponding displacement demands on elastic plastic structures.

Selected test results are presented of eleven full scal shearwalis subjected to cyclic static and shaketable loading. The performance of the sheathing nailing, framing connections and foundation connections is reported in detail. Based on the test observations and an analysis of the force distribution within the framing, particular details are recommended to ensure ductile response. A theoretical time history single degree of freedom dynamic idealisation is described which represents the observed wall behaviour, and which is suitable for incorporation into multistorey analyses.
\end{abstract}

1.

\section{INTRODUCTION}

It is usually uneconomic to design structures to remain elastic during severe earthquake motion. Provided the structure is weil detailed and meets certain requirements inciuding being able to accept displacements greater than that attained at its design load, it can safely be designed to resist horizontal forces substantially iess than those predictedfipr an elastically responding structure (1). Such "ductile" structural components may be rigorously tested to verify that they have this reserve displacement capacity. It happens that well designed reinforced concrete and steel components are able to sustain load levels approximately equal to the design load when cycled through their reserve displacement range and this appears to

* Civil Engineering Department, University of Canterbury. have been effectively adopted as a general performance criterion for seismic load resisting elements. This has sometimes led to the belief that any component having degrading strength and stiffness properties when subject to such cycling loading is unsuitable for ductile type design. However, many types of structures do not exhibit well defined elastoplastic behaviour during cycling. It has been questioned if they should be designed to ductile criteria at all, and if so it is necessary to establish the design level to which they should be designed. Timber structures such as sheathed shearwalls, in which significant nail slips develop before failure, have been qualitatively recognized as having some ductile properties, but their performance during earthquake motion is not well understood.

This is of particular interest currently because it appears to be 


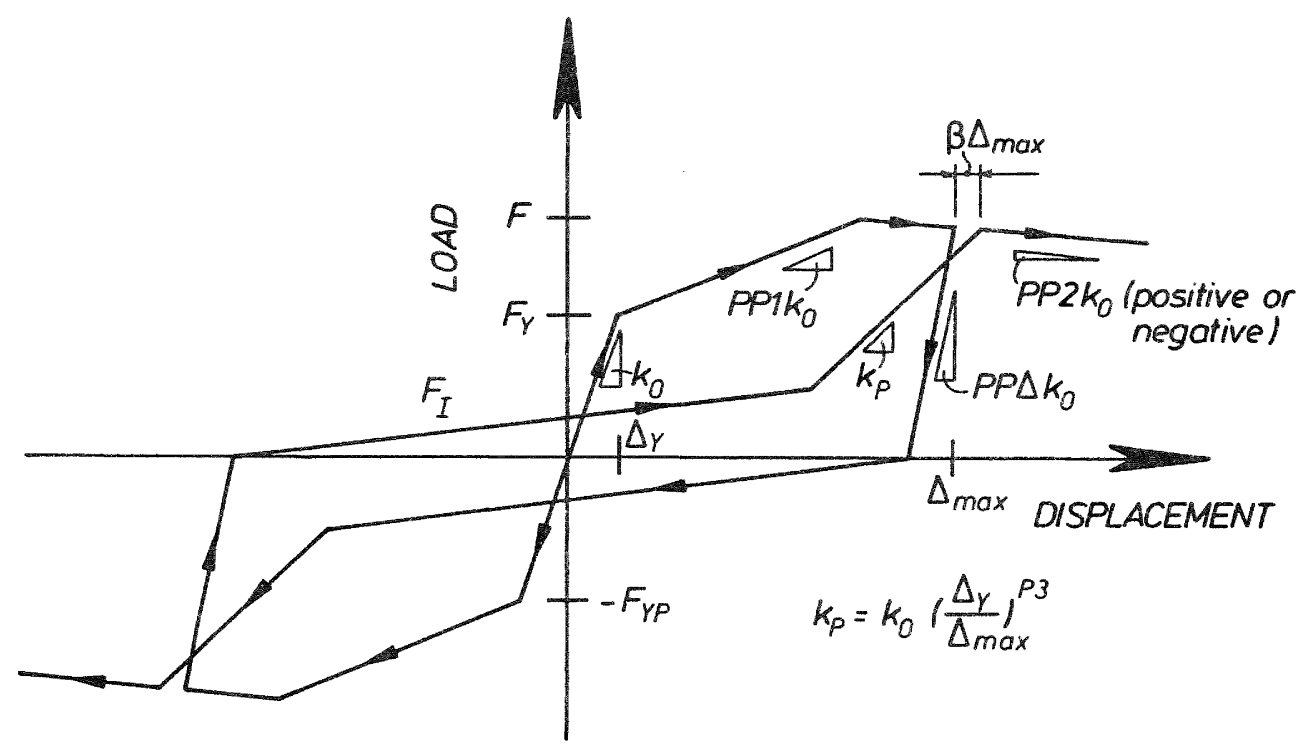

FIG 1 Degrading Hysteretic Idealisation of Sheathed Shearwall.

feasible to erect sheathed structures up to a height of three storeys or more and exploit the economic advantages of light timber frame construction. Large industrial sheathed buildings have already been erected and the concept appears to have particular merit for cellular plan buildings in which internal partitioning contributes to the lateral resistance together with the exterior walls.

The seismic performance of common plywood sheathed frame shearwalls is examined in detail in this paper. Attention is focussed on two fundamental aspects; the displacement demands imposed on sheathed shearwalls by a design level earthquake, and the displacement capacity of the walls themselves. The displacement demand defines the performance requirements to be met and is discussed first. The effect of degrading stiffness characteristics on displacement demand is demonstrated in the following sections by means of a theoretical dynamic timehistory single degree of freedom idealisation which was itself calibrated from shaketable test records.

\section{INFLUENCE OF HYSTERETIC LOOP ON DISPLACEMENT DEMAND}

The influence of the shape of the hysteretic loop on displacement demand was examined using a theoretical timehistory analysis computer program. Figure 1 shows the basis of the degrading hysteretic loop that was developed to idealise the walls, and which is adaptable to other nailed timber structures. The initial loading path follows the initial stiffness $k=k$ up to a yield load $F$, and then reduced stiffnesses PP1 $k$ and PP2 k. For each time step the mass displacement increment is determined from the equation

$$
m \ddot{x}+c \dot{x}+k x=m \ddot{x}_{g}
$$

where $x$ is the relative displacement between the mass and the ground and $x$ is the ground displacement. The visgous damping coefficient $c$ in equation (1) is expressed in the subsequent discussion as the ratio of the critical viscous damping of an elastic oscillator having stiffness $k$. The appropriate stiffness and damping terms in equation (1) are determined by matching the predicted response to that of the test walls subjected to static and dynamic loading. By calibrating the theoretical model response in this way to a 1 imited number of selected ground motion input records. the wall response to other ground motion records and intensities can be predicted. Details of the test records used for the calibration are described subsequently.

Displacement demands for the degrading model were compared with those for the simple elastoplastic model, Fig. 2. To compare the responses of the elastoplastic and the degrading models having the same initial stiffness (and therefore period) to a given seismic ground motion record a nominal yield force $F_{y}$ for both was defined as follows

$$
E_{y}=R F_{E}
$$
where $E_{E}$ is the maximum force developed
in an elastic structure of the same stiffness and period subjected to the same ground motion, and $R$ is a force reduction factor. The force reduction 


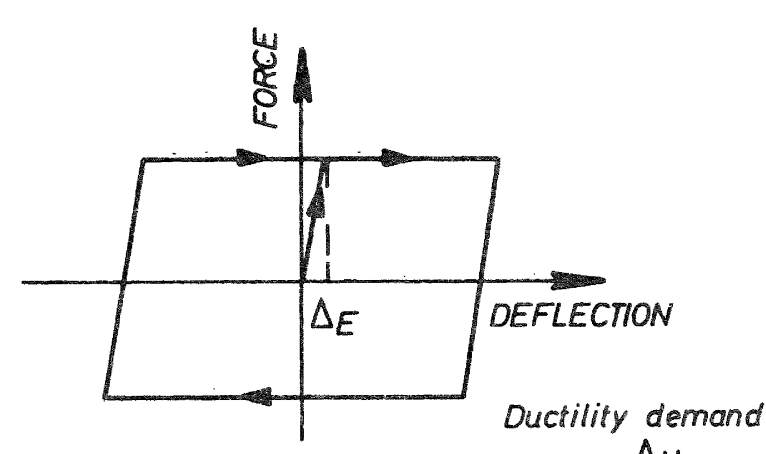

$$
\mu=\frac{\Delta \mu}{\Delta_{E}}
$$

Fig 2 Elasto-plastic Hysteresis Idealisation.

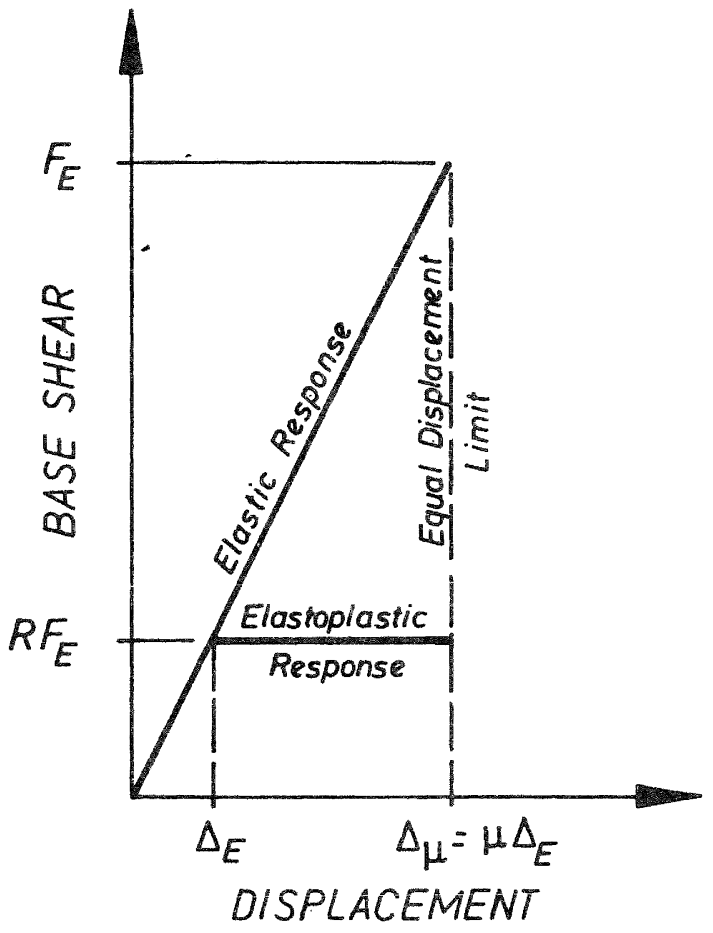

FIG 3 Equal Displacements of Elastic and Elasto-plastic Oscillators.

factor R used in NZS 4203:1984(1) for elastoplastic structures is related to the ductility factor $\mu$ by the equal displacement approximation, Fig. 3. The NZS 4203:1984 design spectrum is based on $\mu=4$ and $R=0.25$, such that the code design force $\varepsilon$ to be used in the strength method of design is $E=E_{E} / 4$, and elastoplastic structures having a yield force $F_{Y}=E=F / 4$ must be capable of a ductility capacity of $\mu=4$. The equal displacement relationship is only a useful approximation to the actual
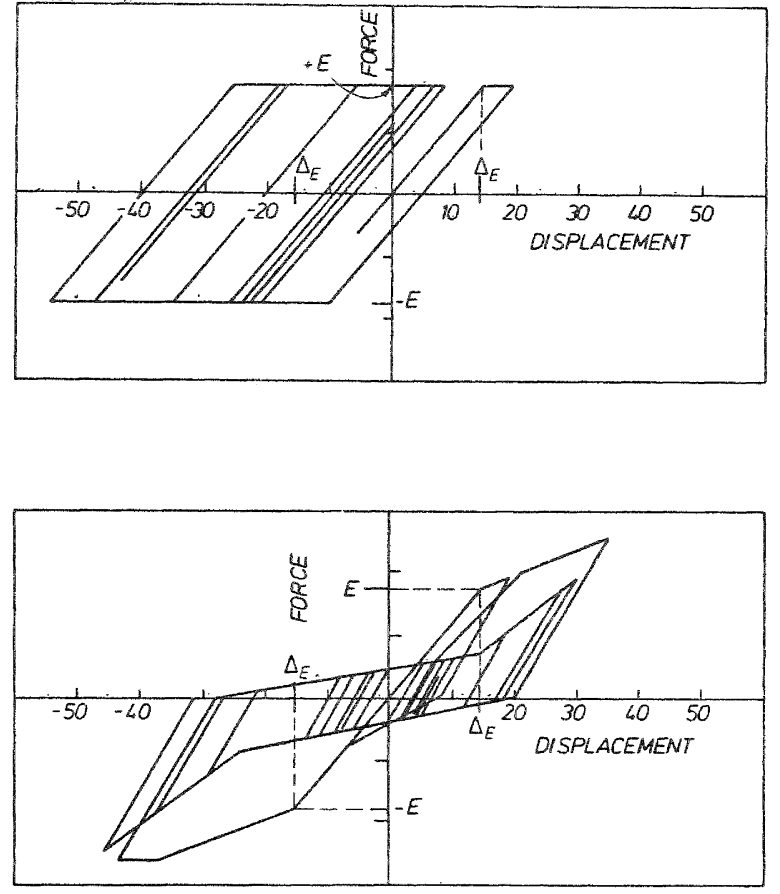

FIG 4 Predicted Shear vs Displacement Response of Elasto-plastic and Degrading Hysteretic Models to El Centro 1940 NS Ground Motion.

displacement demands made on elastoplastic structures and is without any rigorous basis. Figure 4 shows the actual load displacement hysteretic record for both models $(R=0.25,0.6 \mathrm{sec}$ period, $10 \%$ viscous damping) subjected to the El Centro 1940 NS ground motion record. Similar records are generated for other ground motion records including Pacoima Dam and Parkfield. A maximum load of approximately $1.5 \mathrm{~F}$ was attained in the degrading model for each of these cases at maximum displacement. The displacement demands for these particular records are shown in Fig. 5 expressed in terms of the predicted ductility demand u. Eigure 5 shows that ductility demands even for the elastoplastic model exceed the constant displacement $\mu=4$ limit This has already been tacitly recognized in the laboratory ductility assessment of structural steel and concrete elements by ensuring that they are capable of sustaining cyclic load out to displacements of $\mu=6$. Figure 5 also illustrates that ductility demands on stiff structures in the low period range significantiy exceed the constant displacement prediction for the elastoplastic and degrading models. The loading code document currentiy in preparation to supersede NZS 4203:1984 is expected to incorporate increased ductility demand requirements in the low period range.

The displacement demands for the degrading model are not significantly 


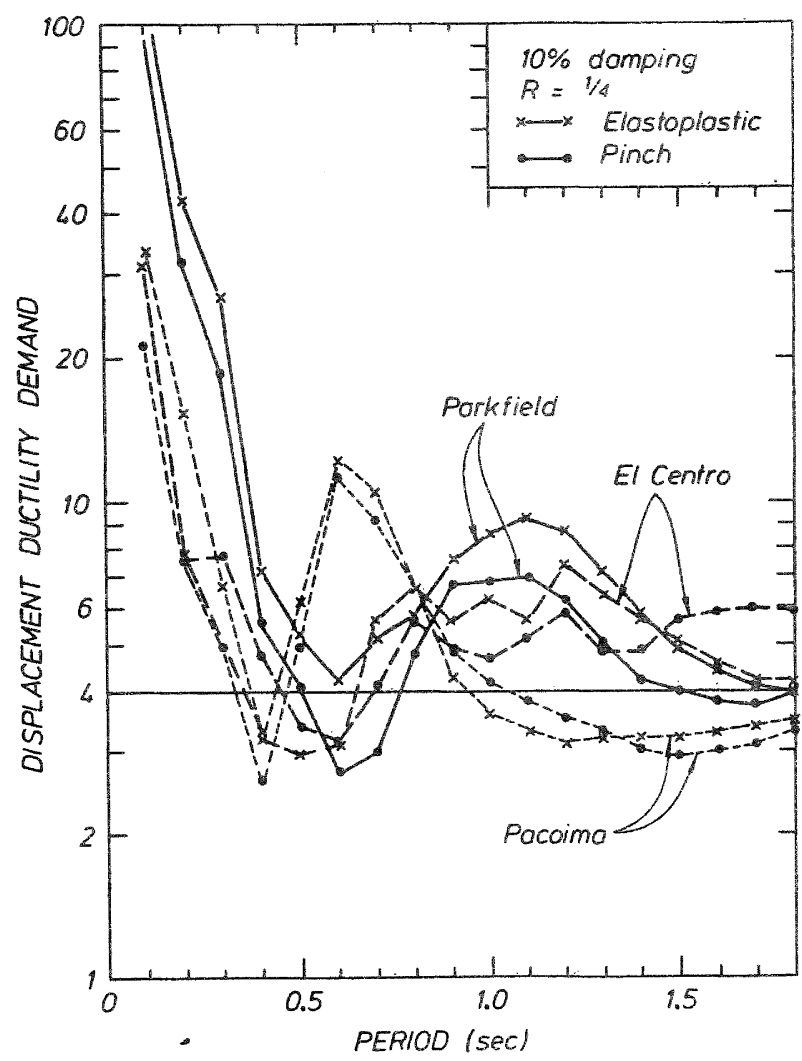

FIG 5 Ductility Demands on Elastoplastic and Degrading (Pinch) Models to El Centro 1940 NS. Pacoima Dam and Parkfield Ground Motion. different from those for the elastoplastic model. The only clear increase in demand, about $25 \%$, is for initial structural periods greater than about 1.5 sec during the El Centro 1940 NS motion. However for other periods and ground motion records the ductility demand is significantly less than the comparable elastoplastic model. Ductility demand for strength reduction factors $R=0.5$ and 0.167 have also been compared for the same range of periods and ground motion inputs, and the trends are similar to those shown in Fig. 5 for $R=0.25$.

The area enclosed by the load displacement hysteretic record during a cycle represents the hysteretic energy dissipation of the structure, and is sometimes referred to as hysteretic damping. The absorbed energy of the degrading model is shown in Fig. 6 as a ratio of that of the elastoplastic model for the range of ductility factor $\mu$. Curve 1 (a) shows that the ratio of dissipated energy of the initial loading cycle, i.e. during loading along the parent monotomic loading curve is between $50 \%$ and $60 \%$. Degradation after repeated loading, curve 1(b), causes this ratio to reduce to between $30 \%$ and $40 \%$. Figure 6 also shows that the energy dissipation ratio reduces with increasing ductility factor. It appears that such reductions in structural energy dissipation have little influence on the total displacement demand. Maximum loads of approximately $1.5 \mathrm{~F}_{\mathrm{y}}$ were attained in the degrading model, despite the degradation of load resistance over most of the displacement range. This strength reserve over and above the nominal yield F clearly favours the degrading model in the comparison between it and the elastoplastic idealisation. Accordingly an adjusted degrading model was developed in which loads exceeding $F_{Y}$ could not be

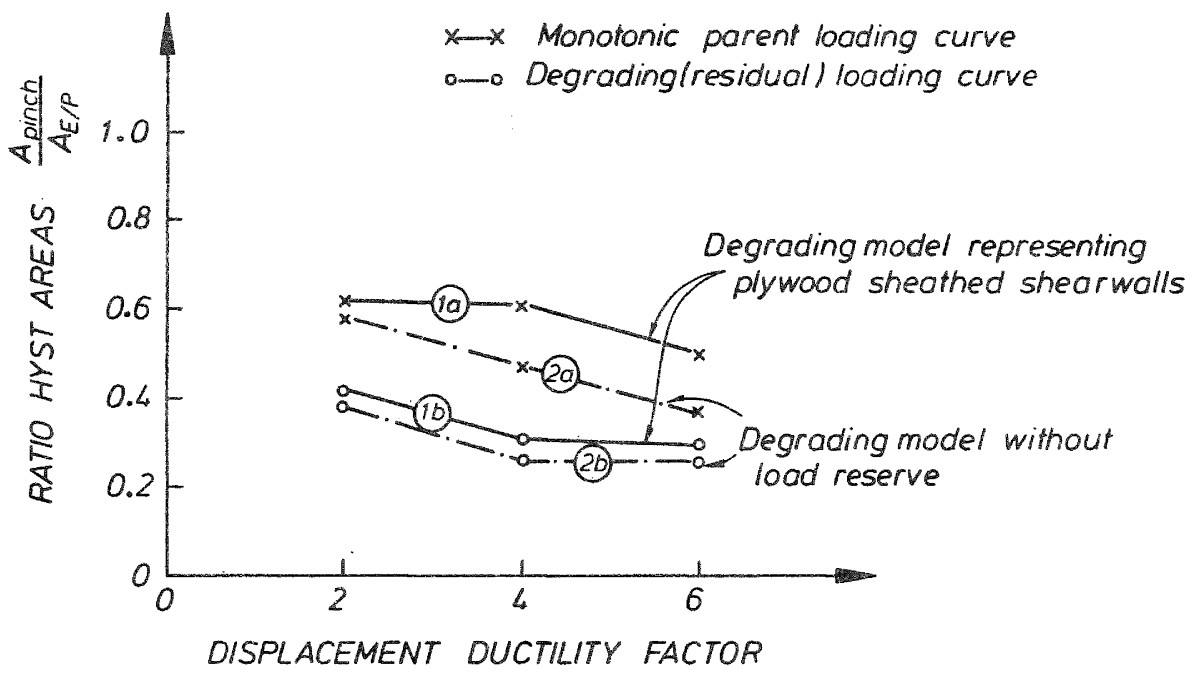



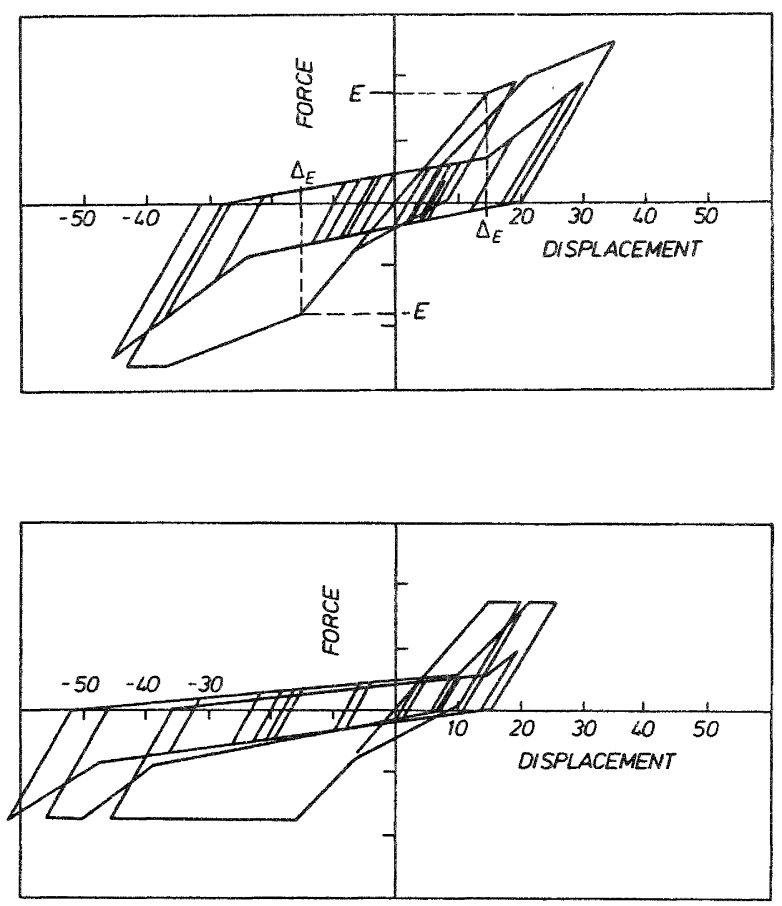

FIG 7 Base Shear vs Displacement Response of Degrading Model With and Without Strength Reserve.

sustained. Figure 7 snows the load displacement record of the adjusted degrading model for 0.6 sec initial period, $10 \%$ viscous damping $R=0.25$ during the El Centro 1940 NS record. For this ground motion the displacement demand for the adjusted degrading model is only $10 \%$ greater than the original degrading mode. Eigure 8 shows the predicted displacement demands for the degrading model with and without strength reserve, and the elastoplastic mode. Displacement demands on the degrading model increase up to $25 \%$ due to the loss of reserve load capacity but nevertheless they are not consistently greater than those for the elastoplastic model.

The natural period $T$ of a slackness oscillator, Fig. 9, representing the degraded hysteretic loop is;

$$
T=T_{0}\left(1+\frac{2}{\pi} \frac{A_{g a p}}{A-A_{g a p}}\right)
$$

where $T$ is the natural period of the oscillator without slackness, i.e. for $A \quad=0$. As an example, for the natural perpod of the degrading model shown in $\mathrm{Fig} .4, \mathrm{~A}=20 \mathrm{~mm}, \mathrm{~A}=33 \mathrm{~mm}, \mathrm{~T}=0.6$ secs, $T=8$ pap secs. Equation ( 29 shows that $T$ increases as $A$ increases during degradation of the wall, and the induced base shear for such increased periods reduces significantly.

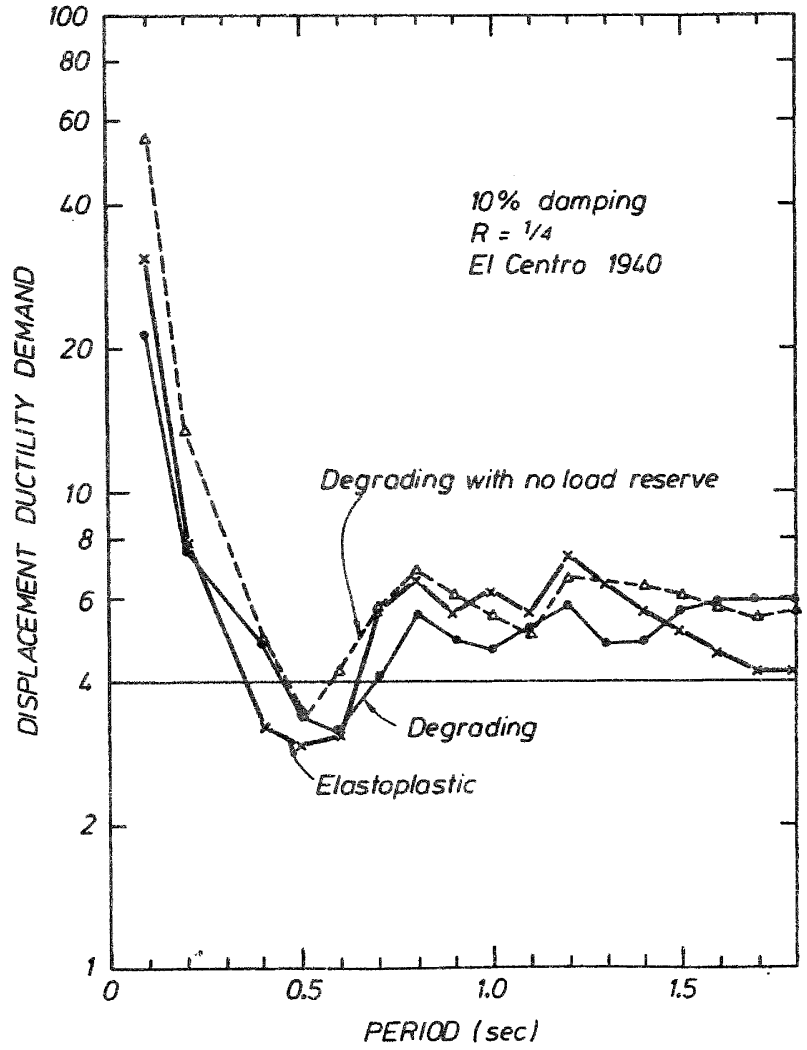

FIG 8 Ductility Demands on Elastoplastic and Degrading Models With and Without Load Reserve; El Centro 1940 NS.

In summary, it appears that the displacement demand for degrading structures with low energy dissipation capacity such as plywood sheathed shearwalls, is not significantly greater than that for elastoplastic structures. It appears that the increase in effective natural period as large displacements develop in the inelastic range is the primary mechanism by which base shears are reduced below that for elastic response.

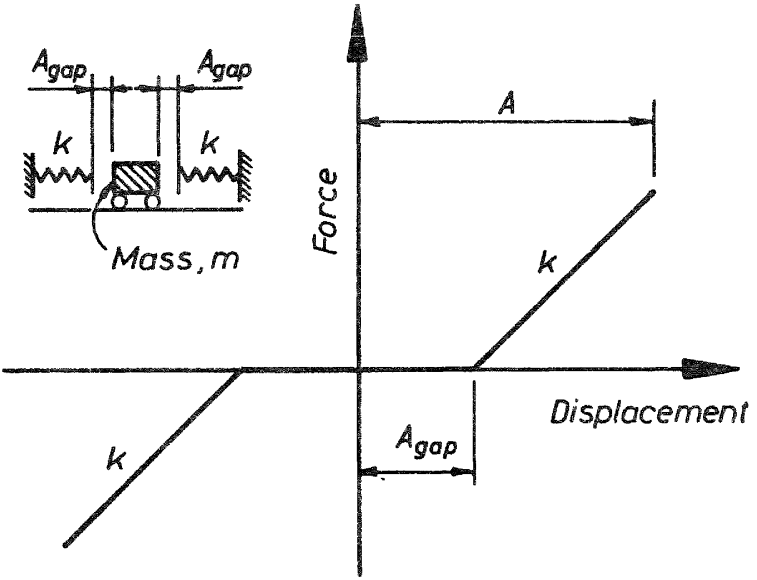

FIG 9 Oscillator with Slackness Gap. 


\section{YIELD CRITERION}

In the case of a truiy elastoplastic structure the elastic stiffness and yield displacement are well defined. However, the recorded load displacement relationship of most structures is curved and the yield and initial stiffness are difficult to define. The yield load and displacement of reinforced concrete elements for example are commonly defined respectively as the theoretical yield load, and 1.33 times the displacement at $75 \%$ of the theoretical yield load. Timber structures in which nail slip contributes significantly to the total displacement exhibit a non-linear response often at low displacements. Moreover the available permissible wind seismic loads for nails in NZS 3603:1981 and NZS 3615:1981 are not based on strength but rather on nail slip criteria.

For consistency between the stated yield load of sheathed timber shearwalls in this paper, and the permissible windseismic nail loads in NZS $3603: 1981$ and NZS 3615:1981, it is proposed here that the nominal yield load of the shearwall $F_{y}$ be 1.25 times the load $F_{\text {s }}$ at which the code permissible wind/seismic nail loads are attained, Fig. 10. This is because NZS 4203:1984 requires that where the "alternative" (i.e. NZS 3603:1981 working stress) method of design is used, the permissible (wind/seismic) load on the structure be $0.8 \mathrm{E}$ where $\mathrm{E}$ is the NZS 4203:1976 seismic design force. This implies that 1.25 times the permissible wind seismic nail loads are attained at a seismic design force $E$ (in the absence of other loading). Secondly, the shearwall tests described in the subsequent sections show that nail forces were reliably sustained up to wall loads of $1.5 F=1.5 \mathrm{E}$, i.e. $1.5 \times 1.25=1.9 \times$ permissible wind-seismic. Wall loads of $1.5 \mathrm{E}$ were not exceeded in the computed predictions and it appears that setting of the nominal yield at $1.25 \mathrm{~F}$ is reasonable. The 1.25 factors is inherently dependent on the chosen NZS 3603:1981 criterion for the permissible wind seismic nail force, and cannot be generally applied to permissible nail loads in other codes.

To ensure ductile behaviour in the sheathing nailing the sheathing itself, framing, foundation connections and other load carrying elements in the load path must be at least capable of resisting an induced load of 1.5E, i.e. 1.9F WS Indeed the maximum capacity of the sheathing nailing itself may exceed $2 \mathrm{~F}$ and the other elements should have this minimum strength. NZS 3603:C1. 2.12 recommends that the strength of framing timber be taken as 2.2 times the BWS values given in NZS 2603:Table 2, and the inplane strength of plywood sheathing may be assumed to be three times the BWS capacity. The design of the foundation hold-down connections requires special care to ensure cyclic loads of $2 \mathrm{~F}$ can be sustained without excessive silp or degradation. This aspect is discussed subsequently.

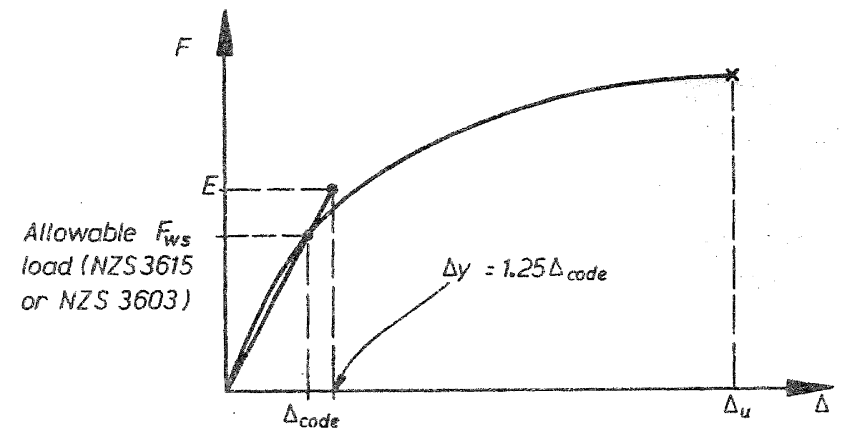

Fig 10 Typical Parent Load vs Displacement Curve for a Nailed Timber Structure Showing Nominal Yield Lueve1.

\section{SM EACTORS OF TIMBER STRUCTURES}

NZS 4203:1984 requires the lateral load $E$ on a structure restraining a seismic weight $W$ be calculated as;

$$
E=S M I R C_{d} W
$$

in which the base shear coefficient $C$ may be expressed in terms of previously derined terminology as

$$
C_{d}=\frac{1}{4} \frac{F_{E}}{W}
$$

The importance and risk factors $I$ and $R$ may be assumed as unity for the type of structures considered here. In recognition that some structural elements may not possess a displacement capacity of four times their yield displacement or alternatively that their behaviour is not truly elastoplastic, the structural type and material factors $S$ and $M$ are also included in equation 3. NZS 3603:1981 simply specifies values of the product SM for different structural timber elements, and for consistency with NZS 3603:1981 and NZS 4203:1984 the design load levels on timber sheathed shearwalla is expressed in terms of the SM factor in this paper too. SM factors for different structural types necessarily lie in the range of between one (for elastoplastic elements with ductility capacity of four or more) to a maximum of four (for purely elastic responding structures without reserve displacement capacity above their nominal design load displacement). For reasons discussed below, the NZS 4203:1984 seismic design loads on elastic timber structures are specified as $S M=$ 2.4. NZS 4203:1984 currentiy specipies $S M=1$ for sheathed timber shearwalls, although even at the time this was included in the code it was understood that further studies were needed to justify it. 
54

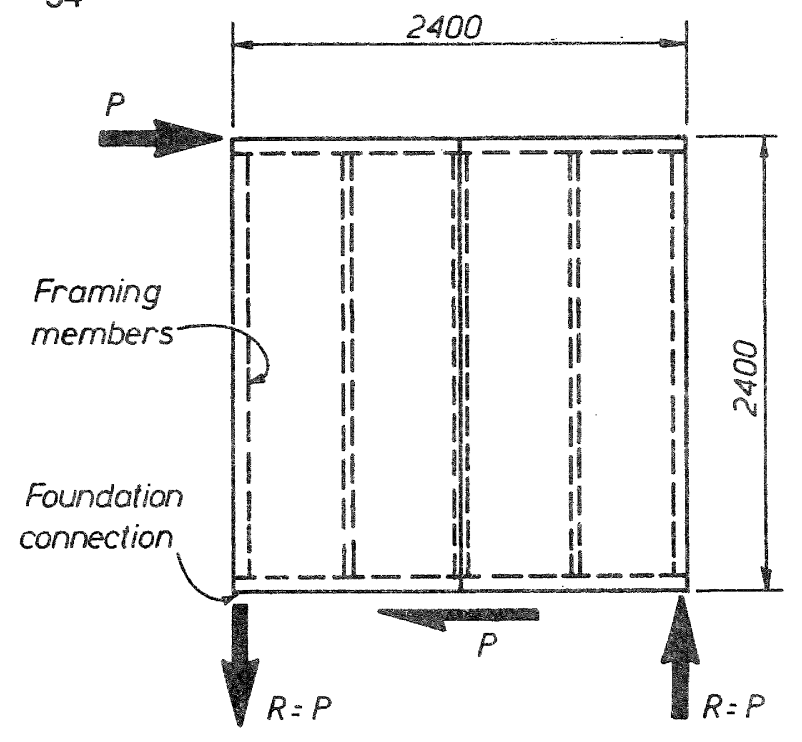

FIG 11 Shearwall Components.

\section{RELATIVE STRENGTHS AND EAILURE}

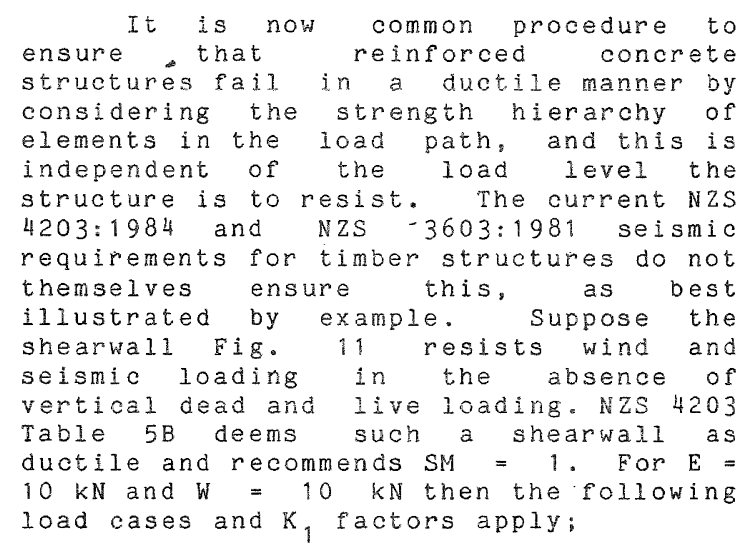

$$
\begin{array}{ll}
\text { Load combination } & K_{1} \\
D+L_{R}+W=10 \mathrm{kN} & 1.5 \\
D+L_{R}+0.8 E=8 \mathrm{kN} & 1.5
\end{array}
$$

It may appear that wind loading governs and that the following structural elements should be provided;

$\begin{array}{llcl}\text { Framing members } & : & 6.7 \mathrm{kN} \\ \text { Sheathing members } & : & 10 \mathrm{kN}\end{array}$

Proprietry metal strap

foundation hold-down

connections at permissible

wind-seismic : $10 \mathrm{kN}$

The design is next strictly required to be checked by the NZS 3603:C1. 2.12 seismic loading provisions, despite the implication in NZS 4203:Table $5 B$ that the shearwall is ductile. NZS 3603:C1. 2.12 itself implies that the

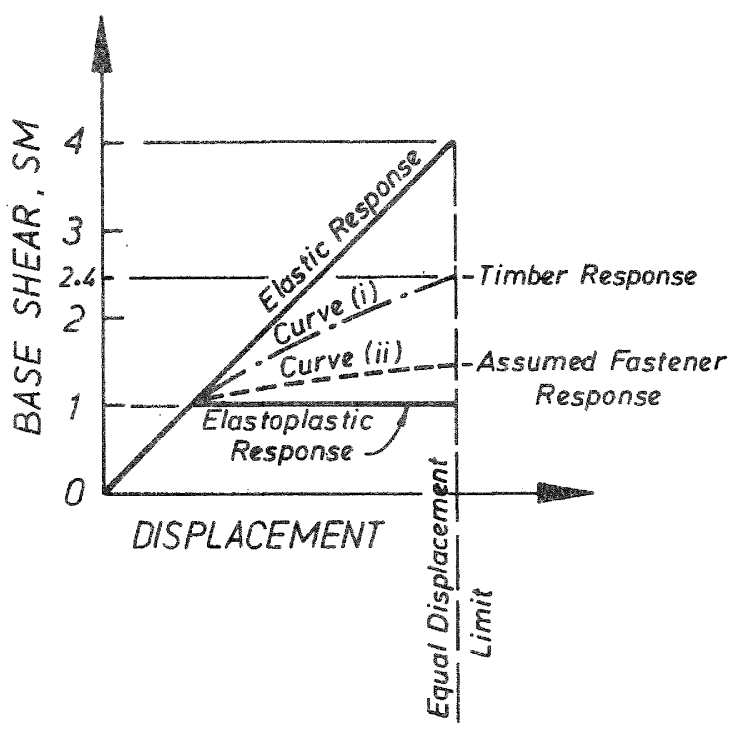

Fig 12 Seismic Response Levels Implicit in NZS 3603:1981 for Timber Structures Designed to $\mathrm{SM}=1$.

actual seismic load on timber structures can exceed the design load $E$ where this is based on $S M$ values less than 2.4 , see Fig. 12, and the requirements are intended to prevent brittle failure. According to NZS 3603:Cl. 2.12 a structure in which most of the flexibility arises from timber strains rather than joint deformation will be subjected to forces $S M=2.4$ at the equal displacement limit, in recognition of the nonlinear response of the timber itself, Fig. 12, curve (i). However if the fasteners' ultimate strength is less than $S M=2.4$, the response shown in curve (ii) Fig. 12 is assumed. NZS $4203: C 1.2 .12$ requires the lower 5\% ile timber strength, calculated as 2.2 BWS, to exceed the lesser of the $S M=2.4$ or rastener ultimate loads. For this to be valid, the fasteners must also have a displacement capacity at least equal to the equal displacement limit.

The following typical ultimate
strength estimates are required for
assessing the shearwal example in
accordance with NZS $3603: C 1.2 .12$;
Framing timber; $(2.2$ BWS)
Sheathing nailing; say $2 \times$
permissible wind-seismic
Foundation hold-down connec-
tions; (wind-seismic load)/
O.6* 6.0
(usual ratio for proprietry
connections)

and for $S M=2.4$ applied lateral load $=$ 2. $4 \mathrm{E}=24.0 \mathrm{kN}$.

The example therefore does not comply with NZS 3603:C1. 2.12 and to do so the framing timber strength would need 


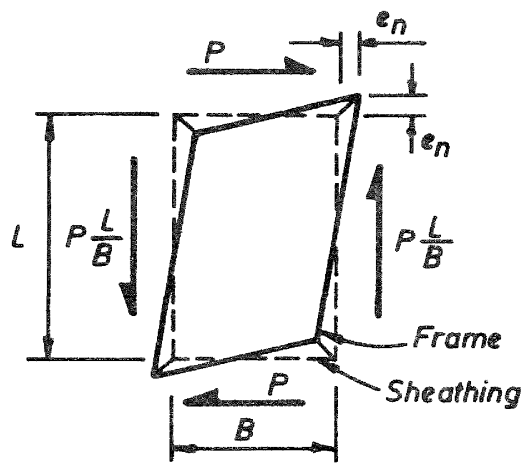

SIMPLE DIAPHRAGM THEORY

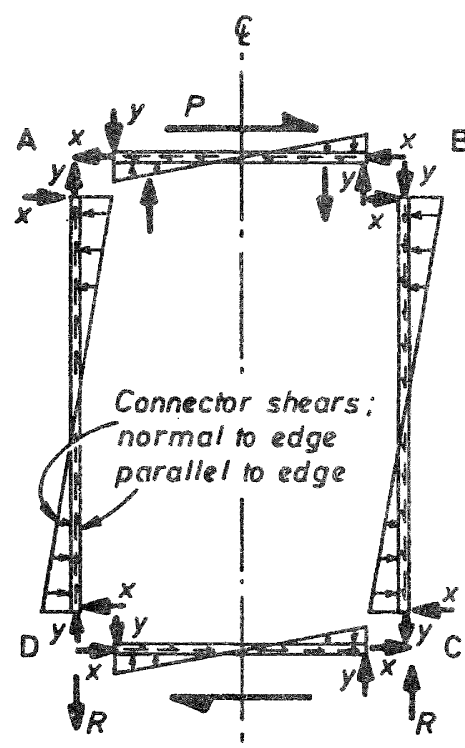

FORCE DISTRIBUTION IN FRAME

FIG 13 Displacements and Forces in single panel shearwall.

to exceed the least strength of the fasteners. In this case, the timber strength is attained at a load only $30 \%$ greater than the permissible wind-seismic load on the sheathing nails, and at this the latter would be comparatively stiff (certainly for the first major excursion). The response would therefore be expected to follow curve (i) in Fig. 12. resulting in brittle timber failure.

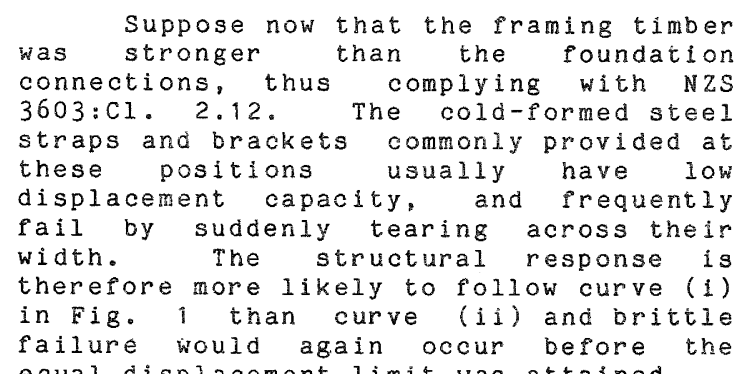
equal displacement limit was attained.

The example illustrates the general trend that there is typically significant strength reserve above permissible nail wind-seismic values, (about two times or more) but less for the timber $(2.2 / 1.5=1.5)$. The problem is accentuated where permanently applied dead and live laod levels are low or zero as in the example but this is typical of shearwalls. Clearly even compliance with NZS $3603: \mathrm{Cl}$. 2.12 does not prevent brittie failure.

\section{SHEARWALL ANALYSIS}

6.1 Shearwall Nailsilp and Displacement idealised as pinjointed rigid framing members connected to rigid sheathing panels by flexible rail connections, the later being sufricientiy closely spaced to be idealised as a continuous connection. In the following analysis it is assumed that all deformation arises from nailsilp. For a uniform shear flow $\mathrm{V}=\mathrm{P} / \mathrm{B}, \mathrm{Fig}, 13$, and for uniform nail spacing c assume that the frame distorts to the shape $A B C D$ Eig. 13 (the load $P$ is imposed on the frame). The force per nall along all frame members is vo causing nailslip e.

The shear distortion strain $\gamma$ between the frame members is then:

$$
r=\frac{e_{n}}{\frac{L}{2}}+\frac{e_{n}}{\frac{B}{2}}=2 e_{n}\left(\frac{1}{L}+\frac{1}{B}\right)
$$

If the bottom erame member is fixed to the foundation as in practice then the wall deflection $\Delta$ is;

$$
\Delta=\gamma_{L}=2 e_{n}\left(1+\frac{L}{B}\right)=2 e_{n}(1+\alpha)
$$

where $a=\mathrm{L} / \mathrm{B}$.

NZS 3603:Table 29 includes formulae for the additional displacements arising from shear strains in the sheathing itself and arial strains in the framing members.

\subsection{Shearwall Framing Forces}

The shear transfer from the sheathing to the framing members is shown in Fig. 13. The applied load $P$ acting along the top framing member is resisted by shear paraliel to the edge, and shear 
stress in the sheathing transfers this shear into the vertical frame members, this in turn resisted by the foundation reactions $R=P$ L/B. Shear is transferred through the bottom framing member into the foundation.

The nail shears acting in a direction normal to the edges, Fig. 13 induce the internal connection forces $X$ and $Y$ between the framing members and the magnitude of these is shown in Table 1 .. Sheathing is usually laid up with a height to width aspect ratio $\alpha=2$. For this aspect ratio, Table 1 , there are tension forces horizontally $\mathrm{X}=0.2 \mathrm{P}$ prising the left hand stud away from the top framing member, and vertically $Y=$ $0.1 \mathrm{P}$ lifting the top framing member away from the left hand stud. $Y$ is a compressive force at $B$ but $X$ forces the stud to the right of the top framing member at $B$ also. The $X$ and $Y$ forces are relaxed by bending of the frame members in the plane of the wall 4$)$.

Where the shearwall comprises two or more sheathing panels the $R$ and $Y$ forces self equilibriate at the internal studs but the $X$ forces are superimposed.

$\begin{array}{clc}\alpha=L / B & X / P & Y / P \\ 0.5 & 0.071 & 0.143 \\ .1 & 0.125 & 0.125 \\ 2 & 0.20 & 0.100 \\ 3 & 0.25 & 0.083 \\ 4 & 0.29 & 0.071\end{array}$

TABLE 1

\section{TEST PROGRAMME}

7.1 Test Wall Design and Detailing

Eleven plywood sheathed walls were tested in the Civil Engineering Laboratories at the University of Canterbury. Experimental records are currently being processed and only selected results are included here together with a general discussion on the performance of the walls. The general arrangement of the walls is shown in Fig. 12. All were framed with ex $150 \times 50$ green-gauged pinus radiata (mc $=12 \%$ ) and sheathed on one side only with DD grade plywood of either 7.5 or $12 \mathrm{~mm}$ thickness. Details of the plywood and sheathing nailing are given in Table 2 together with the type of loading to which they were subjected. The SM ratings in Table 2 were calculated in accordance with the NZS 4203:1984 procedure summarized previously taking $C_{d}=0.15$ for Zone $A$.

The walls were grouped into three test categories, Table 2. Walls S1 to S4 were statically loaded to monitor the load displacement characteristics and overall strength, and the behaviour of joints between the framing members and also the foundation connections. To observe sustained dynamic behaviour and to calibrate the theoretical time-history model, Walls 55 to $\$ 8$ were subjected to dynamic shaketable sinusoidal ground motion. The sustained dynamic loading during this type of ground motion input allows more accurate calibration of the theoretical model than earthquake ground

\begin{tabular}{|c|c|c|c|c|c|c|c|}
\hline $\begin{array}{l}\text { Test } \\
\text { group }\end{array}$ & Wal1 & Loading & $\begin{array}{l}\text { Sheathing } \\
\text { thickness }\end{array}$ & $\begin{array}{c}\text { spacing of } \\
2.8 \operatorname{mam}(1)_{\text {dia. nails }}\end{array}$ & Mass $(\mathrm{kg})$ & SM & Remarks \\
\hline 1 & $\begin{array}{l}\mathrm{s} 1 \\
\mathrm{~s} 2 \\
\mathrm{~s} 3 \\
\mathrm{~s} 4\end{array}$ & $\begin{array}{c}\text { Static } \\
= \\
=\end{array}$ & $\begin{array}{c}7.5^{(1)} \\
7.5 \\
7.5 \\
12.0\end{array}$ & $\begin{array}{r}75 \\
150 \\
75 \\
75\end{array}$ & $\begin{array}{l}- \\
- \\
- \\
-\end{array}$ & & $\begin{array}{l}\text { "Multigrip". connectors at framing } \\
\text { connections }\end{array}$ \\
\hline 2 & $\begin{array}{l}\text { s5 } \\
s 6 \\
s 7 \\
s 8\end{array}$ & $\begin{array}{c}\text { Sinusotdal } \\
\text { dynamic } \\
" \\
"\end{array}$ & $\begin{array}{r}7.5 \\
7.5 \\
7.5 \\
12.0\end{array}$ & $\begin{array}{l}75 \\
75 \\
75 \\
75\end{array}$ & $\begin{array}{l}5000 \\
5000 \\
5000 \\
5000\end{array}$ & & $\begin{array}{l}10 \mathrm{~mm} \text { initial slackness in } \\
\text { hold-down connections } \\
\text { Poundation hold-down designed } \\
\text { to permissible stress criteria }\end{array}$ \\
\hline 3 & $\begin{array}{l}\text { S9 } \\
\text { s10 } \\
\text { s11 }\end{array}$ & $\begin{array}{c}\text { E1 Centro } \\
\text { NS } 1940 \\
\\
\end{array}$ & $\begin{array}{l}7.5 \\
7.5 \\
7.5\end{array}$ & $\begin{array}{r}75 \\
75 \\
150\end{array}$ & $\begin{array}{l}5000 \\
5000 \\
5000\end{array}$ & $\begin{array}{l}3.0^{(2)} \\
3.0^{(2)} \\
1.5^{(2)}\end{array}$ & $\begin{array}{l}10 \mathrm{~mm} \text { initial slackness in } \\
\text { hold-down connections }\end{array}$ \\
\hline
\end{tabular}

(1) NZS $3615: 1981$ recomends $2.8 \mathrm{~mm}$ dila. nails in $7.5 \mathrm{~mm}$ plywood.

(2) SM factors given for Group III walls for 5 tonne inertia mass during testing. 


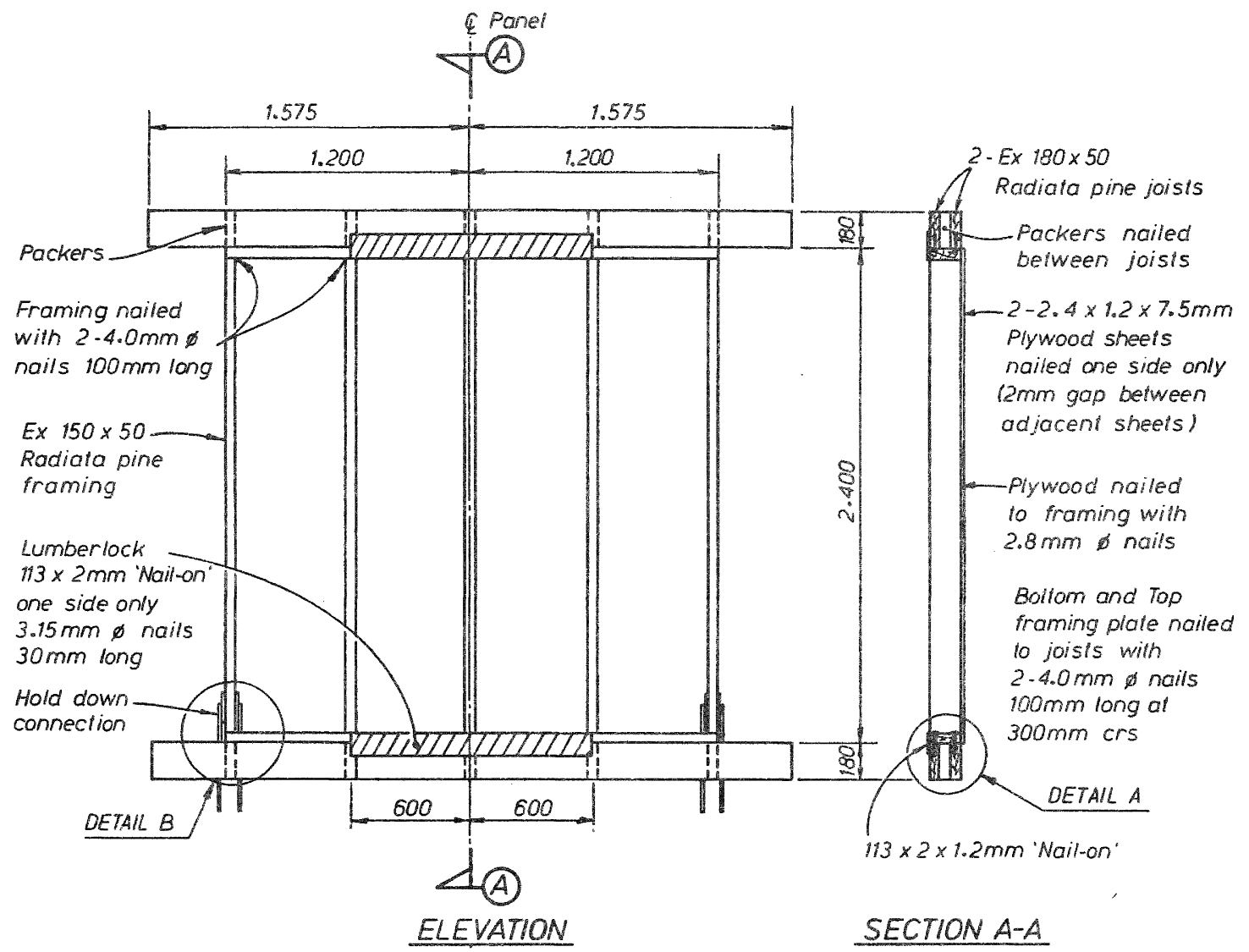

FIG 14 Test Shearwall General Arrangement.

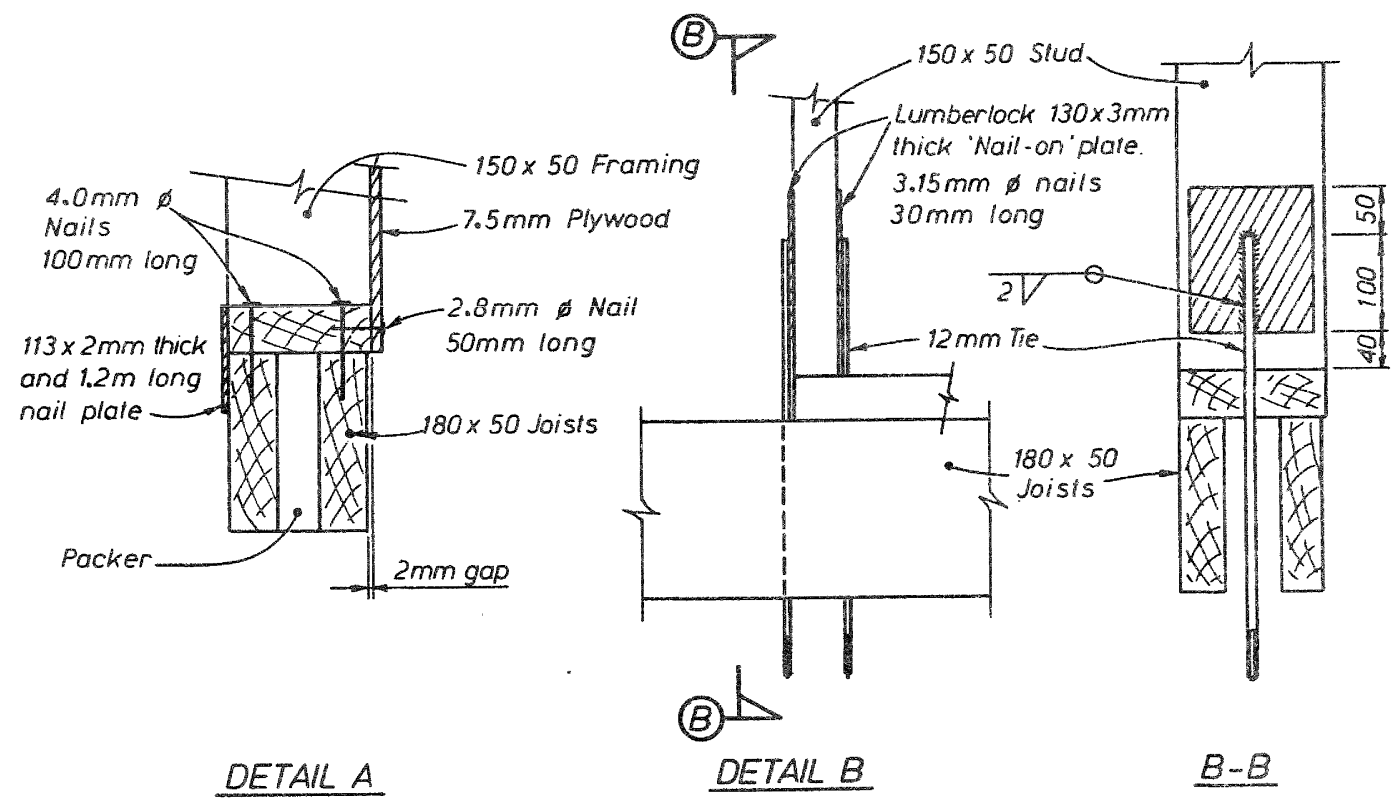

FIG 15 Test Shearwall Details 
motion records would allow. The viscous damping level (c in equation (1)) to be used in the theoretical model was of particular interest. The final group of walls, S9 to S1l, was subjected to El Centro ground motion records to verify the theoretical model predictions.

Within each of the three groups a range of nalling patterns and initial slackness were incorporated as detailed in Table 2. The initial slackness in this case has practical importance in representing actual gaps between the load carrying framing members and at the foundation connections, that can arise during shrinkage of the framing after erection.

The $3650 \mathrm{~kg}$ inertia mass laterally restrained by the Group II and III test walis during the dynamic testing was itself vertically supported by vertical pinned steel arms, such that the test walls were not subjected to vertical loading. This was intended to reflect the relatively low vertical loading in many situations light framing is used. The no-load case was considered the worst for some of the critical connections between the framing and foundations which are subjected to tension during lateral loading, Fig. 11. The hold-down connections in Fig. 15 were chosen for the test,walls after a preliminary series of tests on foundation conpection details commonly used in practice 4 . The

Fig. 15 detail incorporates a steel $3 \mathrm{~mm}$ Nailon plate welded directly to $12 \mathrm{~mm}$ steel ties attached to the foundation frame. Low eccentricity of the tie force with respect to the stud is a feature of this preferred detail. Preliminary tests showed that hold-down connections incorporating bolted brackets or pept Nailon straps did not perform well respect to the stud surface did not exceed $25 \mathrm{~mm}$ in some of these common details, eccentricity led to local fallures in the brackets themselves and crushing of the stud under the brackets. Furthermore where only one bracket is provided rather than two as in Fig. 15 there is danger of flexural failure of the stud itself if the eccentricity exceeds about $25 \mathrm{~mm}$ with respect to the stud surface. Sufficient nails were driven through the Nailon plate to ensure ductile yielding of the tie in Fig. 15 rather than nail failure in the event of overloading of the connection.

\section{$7.2 \frac{\text { Quasi Static Cycling of }}{\text { Group I Walls }}$}

Figure 16 shows the cyclic load vs displacement behaviour of Wall S1 and this is generally representative of the other statically tested walls having 7.5 $\mathrm{mm}$ sheathing, i.e. S2 and $\mathrm{s} 3$, Table 2. The displacement contribution from the foundation connection movement has been subtracted from the total displacement to isolate the hysteretic behaviour of the shearwall itself. The resulting displacement in $F i g .16$ is referred to here as the lozenging displacement. For all three of these walls, the foundation connection displacements contributed a further 25\% over and above the lozenging displacements shown. The walls remained essentially elastic up to $15 \mathrm{~mm}$ lateral displacement with little sign of stiffness degradation, and at this displacement the sheathing nail loads were approximately $10 \%$ greater than the permissible NZS 3603:1981 wind-seismic

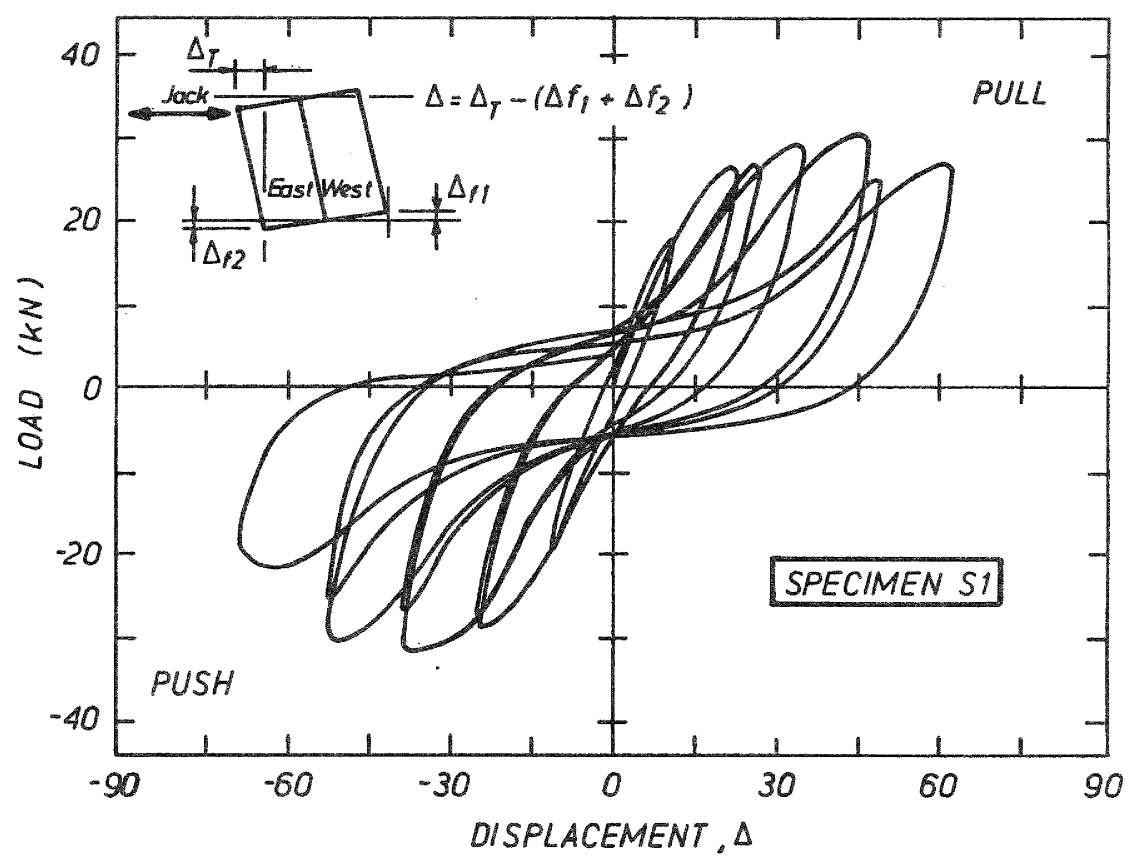

FIG 16 Wall Sl, Static Load vs Lozenging Displacement. 
nail loads. NZS 3603:Fig. 20 indicates $0.9 \mathrm{~mm}$ nail silp at the permissible wind seismic nail load, and the use of this value together with the NZS 3603:1981 value for the sheathing shear modulus Bives a realistic estimate of the measured stifiness of the wall. A general 25\% increase for the roundation connection contribution may then be added to this.

At $30 \mathrm{~mm}$ displacement the sustained load increased to $60 \%$ above the permissible wind seismic load $\mathrm{F}_{\text {WS }}$ *

The sequential increase of displacement at every second cycle as shown in Fig. 16 illustrates a general characteristic of ductile nailed structures. The load follows a parent curve on first loading and during this the wood fibres around the nails crush leaving a cavity in which the nail is unsupported during subsequent loading cycles within this displacement range, Fig. 17. The subsequent residual strength of the wall in this range arises solely from the strength of the sheathing nails acting as cantilevers over the height of the cavity. As the previous displacement is exceeded the nails once more take up bearing against the wood fibres and loading proceeds along the parent curve as it would during monotonic loading. There can consequently be extensive cyciing and degradation during cycling within a specified displacement range, without adversely affecting the load carrying capacity at higher

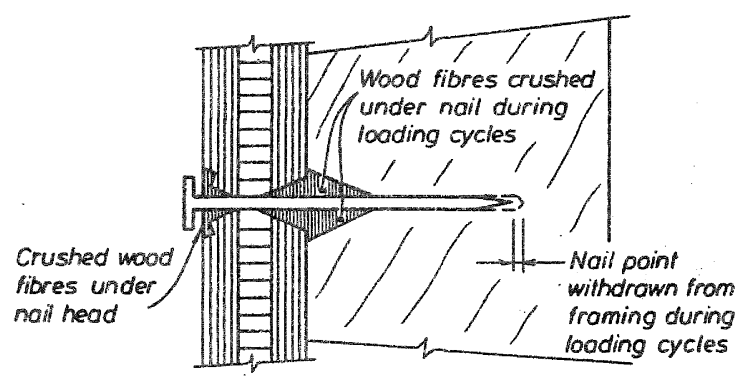

FIG 17 Cavities in $7.5 \mathrm{~mm}$ Plywood and Framing Adjacent to the Nailing After Load Cycling.

displacements. The parent curves in Fig. 18 are therefore relevant to both monotonic and cyclic loading. The maximum load in Walls 51 to 53 developed between 30 and $45^{\circ} \mathrm{mm}$ lozenging displacement, and the maximum load itself was about $1.8 \mathrm{~F}$. The $7.5 \mathrm{~mm}$ thick plywood sheathing of wall si buckled at this displacement without markedly reducing the sustained load. Load was sustained by the walls up to $75 \mathrm{~mm}$ displacement, Fig. 18 and although up to $40 \%$ less than the maximum load, was nevertheless greater than the NZS 3603:1981 permissible wind-seismic load.

The shearwall analysis of section 6 indicates that uniform nail slip can be

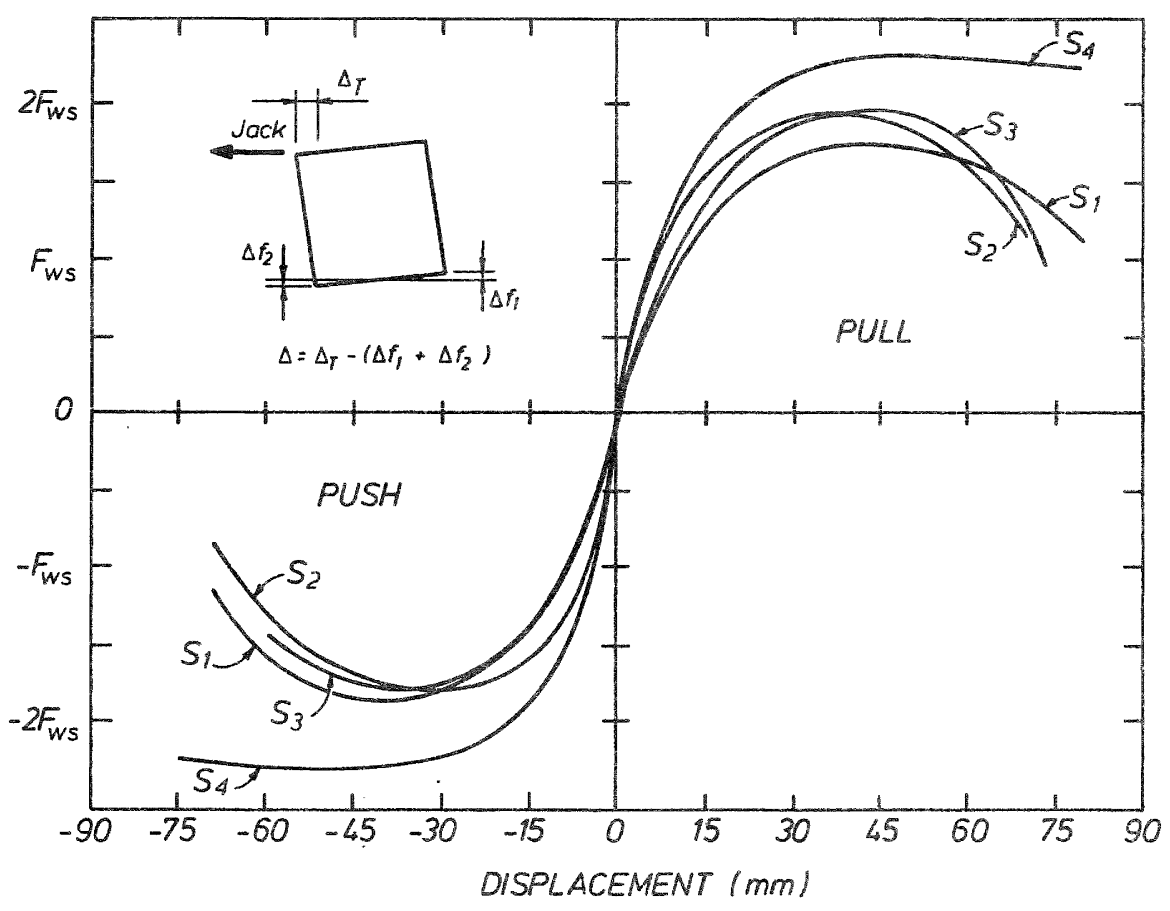

FIG 18 Parent Static Load vs Lozenging Displacement Curves

for Walls SI to S4. Load Expressed in Terms of NZS 3615:1981

Permissible wind/Seismic wall Load $F_{W^{\circ}}$ 
expected around the edges of each plywood sheet and that this slip is one sixth of the wall lozenging displacement where the individual sheathing panels are of $2: 1$ aspect ratio. This was verified up to wall lozenging displacements of about 50 $\mathrm{mm}$ in the tests, but thereafter there was a tendency for the nail slip along one edge of each sheet to dominate without further silp increases along the other edges. This occurred because as the incremental stiffness in one nall line became only marginally less than that of the others, nail slip increased there at the expense of the other nail lines. Consequently, at the maximum wall displacement of $75 \mathrm{~mm}$, nail slips up to $20 \mathrm{~mm}$ had developed in the weakest nail lines of each panel, and nall fallure either by nail pullout or local fibre damage around the head had occurred.

At wall displacements above that at maximum load, e.g. 30 to $45 \mathrm{~mm}$, Eig. 18 there is therefore a risk that nail slips in some localised regions may be much greater than the average. To generally expect reliable load carrying capacity in walls sheathed with $7.5 \mathrm{~mm}$ plywood at higher displacements would be imprudent.

Wall $S 4$ was identical to $\mathrm{S} 1$ and $\mathrm{S} 3$ having the same nail diameter and spacing, but $12 \mathrm{~mm}$ plywood sheathing replaced the $7.5 \mathrm{~mm}$ plywood. Accordingly the NZS 3603:1981 permissible wind seismic load was equal to that of Walls $S 1$ and $S 3$. The load displacement response Fig. 19 indicates improved stiffness and strength properties compared to $\mathrm{S} 1$ and $\mathrm{S} 3$ and a more stable parent curve out to 75 $\mathrm{mm}$ lozenging displacement.
The 54 sheathing nails were effectively fixed against rotation by the thicker plywood such that double curvature was enforced. This contributed to the enhanced stiffness and strength, and also altered the fallure mode in the nails. All the nails in the $7.5 \mathrm{~mm}$ plywood sheathing failed in single curvature at nall silps between 7 and 20 mm, Fig. 17. At this stage the nail inclination caused the flat heads to embed in the top ply of the sheathing and damage the wood fibres. Significant tension developed in the nail at these large slips and the component of this tension parallel to the slip direction comprised a substantial part of the nail resistance. Failure occurred either by collapse of the plywood around the nail head, abrupt pullout of the nail or nail fatigue. Even repeated cycling at slips less than $10 \mathrm{~mm}$ progressively damaged the plywood around the nail head and nail fatigue occurred after even a few cycles in some cases due to the high curvatures in the nail. The length of the nail near the head appears to be cold worked during forging of the nail head and this probably reduces fatigue life.

In contrast the failure mechanism of the nails in the $12 \mathrm{~mm}$ plywood was more stable. Because the plywood thickness was sufficient to enforce double curvature in the nail there was neither degradation of the fibres around the nail head nor high curvatures near the head of the nail. Tension did develop in the nail as it did in the 7.5 mm plywood nails but because of the much improved grip around the nail head this tension caused puliout of the nail of the

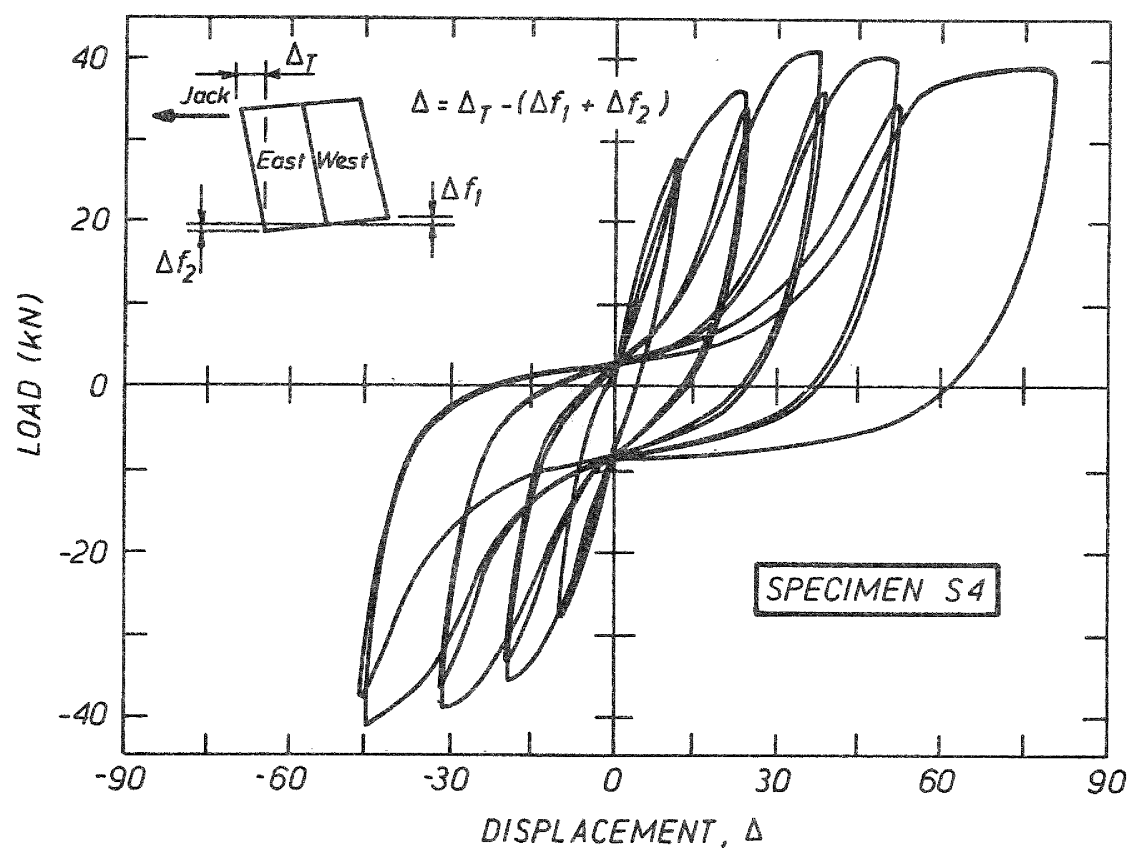

FIG 19 WaI1 $\mathrm{S4}$, Static Load vs Lozenging bisplacement. 
framing only. There are two rather fortuitous characteristics of this
mechanism. Firstly the nail shaft friction forces appear to be maintained even as the nail is being withdrawn from the framing rather than be suddenly released; this may be because of the bent shape of the nail within the framing. secondly as the sheathing returns past the null slip position at the beginning of the cycle in the negative direction, the nail tends to be forced upwards through the sheathing because of the previous withorawal from the framing during the previous cycles. As the slip in the negative direction increases the nail tends to jamb within the sheathing and further withdrawal of the nail from the framing occurs as the negative displacements increase. The outcome of this mechanism is the progressive withdrawal of the nail through the sheathing with the aditional benefit that with each cycle a new part of the nail length lies within the high curvature zone near the interface between the sheathing and the framing.

This nail mechanism was regularly observed during the static and dynamic testing of the walls having $12 \mathrm{~mm}$ sheathing as well as in separately tested joints. A further testing programme is underway to establish whether this mechanism can be relied on when the joint is cycled with the framing green, or made green tested dry. The progressive withdrawal of the nail during cyclio displacements constitutes a valuable ductile mechanism. This benefiolal action would be inhibited if the nail penetration was excessible, suggestin that a maximum length penetration restriction may be necessary as well as the usual minimum length restriction.

Two $100 \times 4.0 \mathrm{~mm}$ nails are commonis provided with connections between framing members, as detailed in NZS 3604 . From Table 1 the predicted uplift force $Y=$ $0.1 \mathrm{P}$ on the top framing member for $\mathrm{P}=30$ $\mathrm{kN}$ as measured in Wall Sl (Fig. 11) is 3 $k N$. This exceeds the pullout strength of the nail pair. The consequential opening of the joint contributed to premature breakdown of the sheathing nails in this region. Angle bracket reinforcement of the corners was only effective if the bracket was recessed into the framing under the plywood sheathing.

The calibration of the theoretical idealisation to the static loading response of Wall $\mathrm{S} 3$ is shown in Eig. 20 , clearly showing the accuracy of the idealisation.

\subsection{Dynamic Testing of Group II and Group III WaIIs}

Those walls in Group II having 7.5 $\mathrm{mm}$ sheathing were subjected to sinusoida ground motion of $45 \mathrm{~mm}$ amplitude, 0.67 sec period $0.4 \mathrm{~g}$ maximum acceleration. Wall S8, having $12 \mathrm{~mm}$ sheathing, was subjected to $60 \mathrm{~mm}$ ground motion displacement, $0.55 \mathrm{~g}$. Wall displacements exceeding $70 \mathrm{~mm}$ were recorded before
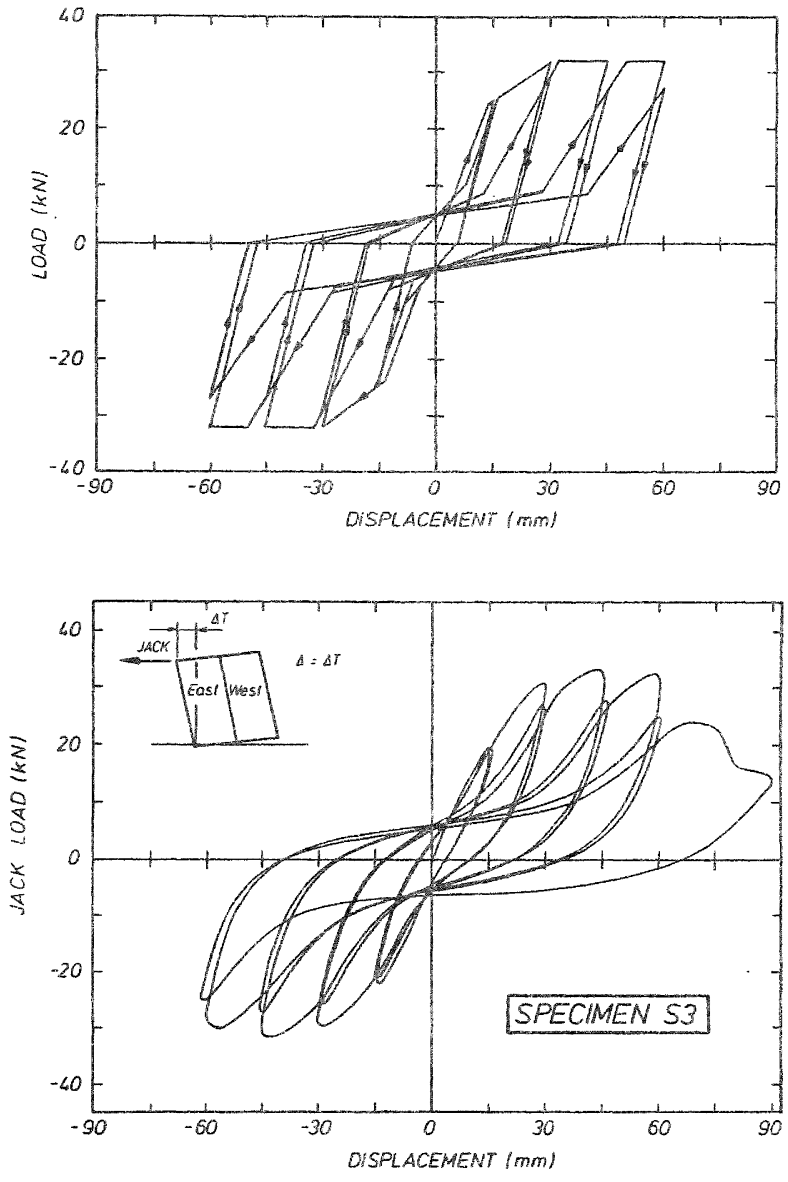

FIG 20 Hysteretic Records of
(a) Theoretical Model and
(b) Test wa11 $\$ 3$
for Displacement Imposed toad Cycling.

eventual failure after two or more cycles. The observed behaviour of these walls was matched by the computer idealisation provided less than 2 . critical viscous damping was incorporated in the theoretical idealisation equation 1. It also appears that dynamio loading rates may enhance strength and stiffness properties.

of the Group III walls the response of Wall SII to El Centro NS 1940 ground motion, maximum ground acceleration 0.5 8 , is shown in Fig. 21. Wall Sil was rated at $S M=1.5$ in accordance with the procedure described in section 4. The wall was subjected to the El centro ground record three times in order to observe its degradation and progressive increase in slackness and the effect of these on dynamic response. Ground displacements and accelerations were increased to 1.2 times the EI Centro magnitudes for the third run, but wall displacements did not exceed $60 \mathrm{~mm}, F i g$. 21. The wall was still capable of carrying lateral load after the testing.

During the pirst test, the maximum positfve and negative displacement 


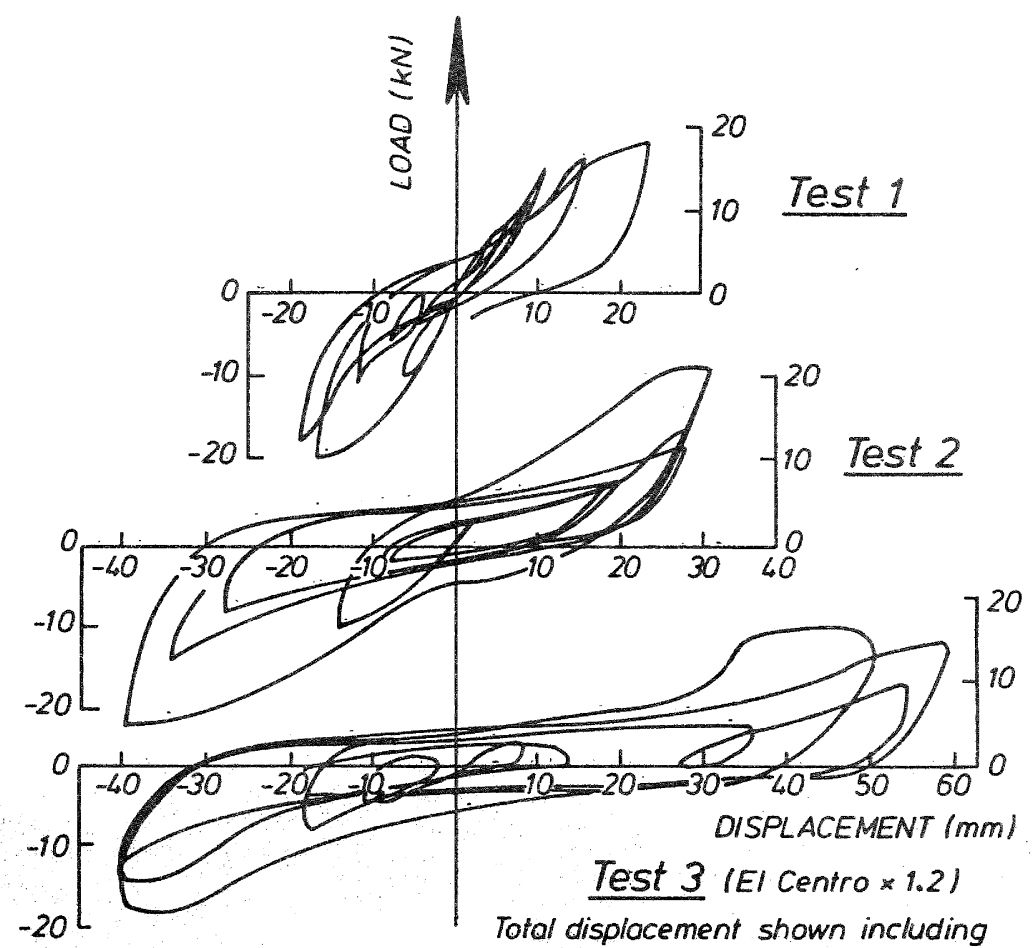

contribution from foundotion connections

FIG 21 Wall S11; El Centro 1940 NS Ground Motion, $S M=1.5$.

excursions follow the parent curve, and it can be argued that the degradation that occurs as the timber fibres crush during these excursions can only effect subsequent excursions in the respective directions. That is, if there is only one major excursion in each direction a degrading structure will perform in a similar manner to one having fat hysteretic curves. The second and third tests on S11 are therefore of special interest in showing the effect on response of previously induced slackness.

\section{CONCLUDING REMARKS}

For sheathed timber shearwalls in which most of the lateral displacement arises from slip of the sheathing nails and which are designed to $S M=1, N Z S$ 4203:1984 seismic design loading, the displacement demand is not significantly greater than that for structures having elastoplastic response. For this comparison the nominal yield force of the walls was taken as $25 \%$ greater than that at which the NZS 3603:1981 and NZS 3615:1981 permissible wind selsmic loads were attained. NZS 4203:1984 design intensity earthquake ground records induce load levels up to twice that at which permissible NZS 3603:1981 and NZS 3615:1981 permissible wind seismic nail loads are reached. Ultimate nail strengths can be expected to exceed this provided the sheathing thickness is at least that recommended in NZS 3615:1981 for the specified nail diameter. However if the plywood is sufficiently thick to ensure double curvature of the nail the ductile properties are much improved.

Displacement demands up to $45 \mathrm{~mm}$ including foundation connection deformation can be expected in shearwalls designed to $S M=1$. If such walls are designed to $\mathrm{SM}=1.5$ displacement demands will not exceed $25 \mathrm{~mm}$. Even if there is significant initial. slackness arising from shrinkage effects or previous overloading, displacements in the latter walls should not exceed $35 \mathrm{~mm}$. Increasing the SM factor, and hence the ultimate strength of the sheathing nails requires the other elements in the load path to be strengthened too. As a useful guide these other elements should be able to sarely resist without degradation twice the permissible wind-seismic load of the sheathing nails. Such a capacity design approach is practical even with our present knowledge of ultimate strength of timber components. The most difficult general area in timber design is the transfer of forces across localised connections between solid timber members. Preferred details for frame member and foundation connections should be published together. with their design load ratings for specified silp limits and at ultimate strength. The sheathing nailing itself comprises the ideal ductile load limiting element having sufficient displacement capacity to allow low lateral design force levels 
In the structure and being easily erected, inspected and repaired.

\section{REFERENCES}

(1) NZS 4203:1984 Code of Practice of General Structural Design and Design Loadings for Buildings, Standards Association of New Zealand.

(2) NZS 3603:1981 Code of Practice for Timber Design. Standards Association of New Zealand.

(3) NZS 3615:1981 Strength Properties and Design Methods for Construction Plywood, Standards Association of New Zealand.

(4) Stewart, W.G., Dean, J.A. and Carr, A.J. The Seismic Performance of Plywood Sheathed Shearwalls. Proceedings of the Pacific Timber Engineering Conference, May 1984, Auckland, New Zealand.

(5) Stewart, W.G. Seismic Performance of Sheathed Timber Shearwalls. PhD Thesis (in preparation). 1986, University of Canterbury, Christchurch, New Zealand. 